\title{
Cognitive Coping and Time Perspective of Post Graduate Students in Relation to Homesickness
}

\author{
Mr. Appasaheb C. Patil ${ }^{1 *}$, Ms. Rekha S. Kulkarni ${ }^{2}$, Dr. Shanmukh V. Kamble ${ }^{3}$
}

\section{ABSTRACT}

The study was conducted to test the significant relation between Homesickness, Cognitive Coping and Time Perspective of Male and Female students studying at Karnatak University Dharwad ( $\mathrm{N}=150 ; \mathrm{M}=75, \mathrm{~F}=75)$. Homesickness Scale (John Archer, Jone Ireland, Su Ling Amas, Helen Broad and Lisa Curri; 1988). Cognitive Emotional Regulation Scale (Nadia Garnetskijon, Teeds Vivion, Kraaji 2001) and Time Perspective Scale (Philip Zimbardo and Boyd 2001) was administered on the sample expressed. Results revealed that the male students have employed acceptance and blaming others as coping strategies to overcome homesickness. On the time perspective, male students having high present hedonistic have expressed homesickness. It was observed that there was no significant relationship between cognitive coping strategy with homesickness in female students, further the female students whose time orientation to future have expressed homesickness and past positive has contributed to homesickness.

Keywords: Cognitive Coping, Time Perspective, Homesickness

Moving from one familiar environment to another strange environment or relocating to a new place for work, education, migration, commerce, etc accompanied with stress. Homesickness is a depression-like reaction and normative pathology and developmental experience that ranges from mild to severe and can be defined as the distress caused by an actual or anticipated separation from home or familiar environment and closed people that redound to ruminations and a strong preoccupation with the former environment and strong longing to return to the previous environment (Eurelings-Bontekoe, Vingerhoets, \& Fontijn, 1994). The key psychological characteristics of homesickness appear to be a strong obsessions with thoughts of home, a perceived need to go home, a sense of deep sorrow for the home, people, place and

\footnotetext{
${ }^{1}$ Research Scholar, Department of Psychology, Karnatak University, Dharwad, Karnataka, India

${ }^{2}$ Post Graduate Student, Department of Psychology, Karnatak University, Dharwad Karnataka, India

${ }^{3}$ Associate Professor, Department of Psychology, Karnatak University, Dharwad, Karnataka, India *Responding Author

(C) 2016, A Patil, R Kulkarni S Kamle; licensee IJIP. This is an Open Access Research distributed under the terms of the Creative Commons Attribution License (http://creativecommons.org/licenses/by/2.0), which permits unrestricted use, distribution, and reproduction in any Medium, provided the original work is properly cited.
} 


\section{Cognitive Coping and Time Perspective of Post Graduate Students in relation to Homesickness}

things and a simultaneous emotions of sadness, despondency, regretfulness and disorientation in the new place which is noticeably, not home. Lindner claimed that about $60-70 \%$ of students that colonize at a university develop feelings of distress and homesickness (Van Tilburg, Vingerhoets, \& van Heck, 1999), of whom 7-10\% develops a severe form of homesickness (Eurelings-Bontekoe, Brouwers, Verschuur, \& Duijsens, 1998). Therefore, homesickness is a common experience among students.

Cognitions and thoughts are very important in their ability to manage or regulate emotions or feelings, and to keep control over emotions and/or not getting overwhelmed by them, for example during or after the experience of threatening or stressful events. Examples of cognitive coping strategies people may use in the experience of negative life events are tendencies to blame yourself for what has happened, to ruminate, to accept what you have experienced, to blame others, to catastrophize or to positively reappraise the situation (Garnefski et al., 2001). Although the capability of advanced thinking and regulating emotions through thoughts and cognitions is universal, large individual differences exist in the amount of cognitive activity and in the content of thoughts of adolescents by means of which they regulate their emotions in response to life experiences, events and stressors. Cross-sectional studies in "general population"' adolescents have shown that, especially, cognitive emotion regulation styles such as self-blaming, catastrophizing and rumination play an important role in the relationship between the experience of negative life events and maladjustment (Garnefski et al., 2001). This finding suggests that by using certain cognitive strategies, adolescents may be more vulnerable to developing psychopathology in response to negative life events or, the other way around, that by using other cognitive strategies, adolescents may more easily tolerate or master negative life experiences.

Since the introduction of Time Perspective (TP) concept it became a challenging one in all fields of applied psychology, as long as researchers get access to some main factors that influence people's decisions and alter their adaptive behaviours. TP was considered by Zimbardo and Boyd (1999) "a fundamental dimension in the construction of psychological time, that emerges form cognitive processes partitioning human experience into past, present, and future temporal frames” (1271). The TP dimensions related to the Past (Past-negative and Past-positive) reflect two different orientations. As Zimbardo and Boyd (1999) noted '... the first factor suggests trauma, pain and regret, the Past positive factor reflects a warm, sentimental attitude towards the past' (p.1274). The Present hedonistic reflects a hedonistic and risk-taking propensity, the person characterized by this dimension being oriented towards present pleasure, with little concern for future consequences. The Present fatalistic reveals a fatalistic, helpless, and hopeless attitude towards the future and life, while the Future dimension of TP includes mental representations of future consequences and concerns, responsibility, striving for future goals and rewards (Zimbardo \& Boyd 1999, Strathman et al. 1994). 


\section{Cognitive Coping and Time Perspective of Post Graduate Students in relation to Homesickness}

After more than a decade from the seminal model of TP (Zimbardo \& Boyd, 1999) a great consensus is emerging in literature, validating cross-culturally the Past negative, Present hedonistic, Future, Past positive and Present fatalistic as five distinct factors (Apostolidis \& Fieulaine, 2004; Milfont et al., 2008; Diaz-Morales et al., 2006).

\section{LITERATURE REVIEW}

Chris R. Brewin, Adrian Furnham and Mark Howes (1989) investigated some of the determinants of homesickness and reactions to homesickness in two samples of first-year English Psychology students who had left home for the first time. Homesickness was found to be a reasonably common but short-lived phenomenon, and was predicted longitudinally by greater self-reported dependency on other people and by higher estimates of the frequency of homesickness among students in general. Although homesickness was equally common in men and women, women were much more likely to discuss their feelings with others and to respond by being more affiliative. Greater anxiety and depression about homesickness were also associated with more confiding behaviour. There was a suggestion that homesick male students were more likely to seek out others, the more common they perceived homesickness.

Christopher A. Thurber and Edward A. Walton (2012) studied on Homesickness and Adjustment in University Students and found out that the students reported depression and anxiety, withdrawn behavior, and difficulty focusing on topics unrelated to home. It exacerbated preexisting mood and anxiety disorders, precipitated new mental and physical health problems, and sometimes lead to withdrawal from school.

Kraaij, V, Garnefski, N, Schroevers, M. J, Weijmer, J and Helmerhorst, F (2010) studied the relationships between cognitive coping strategies, goal adjustment, and symptoms of depression and anxiety in people with fertility problems. Both cross-sectional and prospective relationships were studied in a sample of 313 patients attending an infertility clinic. Self-report questionnaires were filled out at home. Positive refocusing, rumination and catastrophizing, and goal reengagement were related to symptoms of depression and anxiety. When looking at the longterm effects, rumination and catastrophizing were also related to emotional problems nine months later. These findings suggest that intervention programs should focus on cognitive coping strategies and goal-based processes.

Nadia Garnefski Vivian Kraaji (2006) studied the relationships between Cognitive emotion regulation strategies and depressive symptoms. Five specific samples (ranging from adolescents to elderly) were compared on their reported use of Cognitive emotion regulation strategies (Rumination, Catastrophizing, Self-blame, Other-blame, Acceptance, Positive Reappraisal, Putting into Perspective, Positive Refocusing, Planning) and on the relationships between these strategies and symptoms of depression. Although remarkable differences were found in reported 


\section{Cognitive Coping and Time Perspective of Post Graduate Students in relation to Homesickness}

strategies, relationships between Cognitive emotion regulation strategies and symptoms of depression were shown to be similar between the five groups.

Boyd, John N. Zimbardo, Philip G. (2005) summarized some of the research from their laboratory and that of other psychological investigators that has related specific Zimbardo Time Perspective Inventory factors to other established psychological variables and behaviors. They focused heavily on the ways in which future Time Perspective is associated with positive future consequences, notably in the realm of health and risk. In addition, they also pointed out the trade-offs common among those high on present-hedonism, who may live to enjoy the expanded present moment fully but then are more likely to suffer the consequences of failing to invest in health maintenance. The authors also uncoupled dual aspects of present time orientation and past orientation.

A.N. La Roche and A. Frankel (1986) conducted two studies to determine the relationship, if any, between Time Perspective (present versus future orientation) and physical and psychological health. In the first study future-oriented persons reported more physical ailments than present-oriented persons $(\mathrm{P}<0.01)$. In the second study, future-oriented persons indicated they were more anxious on measures of manifest anxiety $(\mathrm{P}<0.01)$ and physical anxiety $(\mathrm{P}<$ 0.05), as well as more depressed $(\mathrm{P}<0.01)$, than present- oriented persons.

\section{METHOD}

\section{Objectives of the Study}

1) To find out the significance of the relationship of Cognitive coping and Time Perspective of male and female students with their Homesickness

2) To find the significant gender differences on Cognitive coping, Time Perspective and Homesickness.

\section{Main Research Problem}

The problem under the investigation comprises the following major questions.

1) Do the Cognitive coping and Time Perspective of the male and female students significantly related to their Homesickness?

2) Do the male and female students differ significantly on Cognitive coping, Time Perspective and Homesickness?

\section{Hypotheses}

Ha $a_{1}$-Cognitive coping and Time Perspective of male and female students are significantly and positively related to their Homesickness.

Ha $_{1} .{ }^{1}$ Self blame, Acceptance, Rumination, Positive reappraisal, refocusing on Planning, Positive re-approval, Putting into perspective, Catastrophizing and Other blame is significantly and positively related to Homesickness of male students. 


\section{Cognitive Coping and Time Perspective of Post Graduate Students in relation to Homesickness}

$\mathbf{H a}_{1}{ }^{2}$ Self blame, Acceptance, Rumination, Positive reappraisal, refocusing on Planning, Positive re-approval, Putting into perspective, Catastrophizing and Other blame is significantly and positively related to Homesickness of female students.

$\mathbf{H a}_{1} .^{3}$ Past Positive, Past Negative, Present Hedonistic, Present Fatalistic and Future is significantly and positively related to Homesickness of male students

Ha $_{1}{ }^{4}$ Past Positive, Past Negative, Present Hedonistic, Present Fatalistic and Future is significantly and positively related to Homesickness of female students.

$\mathrm{Ha}_{2}$ There is a significant difference between the male and female students on Cognitive coping, Time Perspective and Home sickness.

Ha $\mathbf{H}_{2.1}$ There is a significant difference between male and female students on Self-blame, Acceptance, Rumination, Positive reappraisal, refocusing on Planning, Positive reapproval, Putting into perspective, Catastrophizing and Other blame.

Ha$_{2.2}$ There is a significant difference between male and female students on Past Positive, Past Negative, Present Hedonistic, Present Fatalistic and Future

$\mathbf{H a}_{2 \cdot 3}$ There is a significant difference between male and female students on Homesickness.

\section{Sample}

A random sample of 75 male and 75 female students studying in the various department of Karnatak University, Dharwad were selected for the study.

Table showing distribution of the sample in terms of number sex and mean age.

\begin{tabular}{|c|c|c|c|}
\hline Sl No & Sex & N & Mean Age \\
\hline 1 & Male & 75 & 23 \\
\hline 2 & Female & 75 & 23 \\
\hline
\end{tabular}

\section{Tools}

\section{1) Personal Data Sheet}

A personal data sheet was prepared by the researcher to obtain demographic details such as age, gender, domicile, education status etc of the subjects.

\section{2) Homesickness}

This scale was developed by John Archer, Jane Ireland, Su-Ling Amos Helen Broad and Lisa Currid (1998) The alpha ranged from .80 to .86. Likert scales has been used; there are 33 items that are completed by individual whose Homesickness is measured. There are 1strongly Disagree and 5- strongly agree, options for each statement.

\section{3) Cognitive Emotional Regulation}

The CERQ (CERQ; Garnefski, Kraaij, \& Spinhoven, 2001) has 36-items in total and consists of nine subscales: Self-blame, referring to thoughts of putting the blame of what you have experienced on yourself; Other-blame, referring to thoughts of putting the blame of what you have experienced on the environment or another person; Rumination, referring to thinking about the feelings and thoughts associated with the negative event; Catastrophizing, referring to thoughts of explicitly emphasizing the terror of what you have experienced; Putting into 


\section{Cognitive Coping and Time Perspective of Post Graduate Students in relation to Homesickness}

Perspective, referring to downgrading the importance of the event; Positive Refocusing, referring to thinking about positive experiences instead of thinking about the actual event; Positive Reappraisal, referring to thoughts of giving the event a positive meaning in terms of personal growth; Acceptance, referring to thoughts of resigning yourself to what has happened and Planning, referring to thinking about what steps to take and how to handle the negative event. Cronbach's alpha subscale ranges were from 0.64 to 0.82 .

\section{4) Time Perspective}

Zimbardo Time Perspective Inventory (ZTPI; Zimbardo \& Boyd, 1999). To assess time perspective, the Spanish version of the ZTPI (Díaz-Morales, 2006) was administered. This version contains 56 items which are assessed on a 5-point scale ranging from 1 (very uncharacteristic) to 5 (very characteristic). The ZTPI consists of five factors: Past-Negative, Present-Hedonistic, Future, Past-Positive and Present- Fatalistic. 1) The Past-Negative scale (10 items): reflects a generally negative, aversive view of the past (i.e.: "Painful past experiences keep being replayed in my mind”, “I've made mistakes in the past that I could undo”). 2) The Present- Hedonistic scale (15 items) reflects a hedonistic, enjoyment and pleasure centered risk-taking attitude toward time and life (i.e. "I take risks to put excitement in my life”, “I make decisions on the spur of the moment”). 3) The Future scale (13 items) reflects a general orientation toward the achievement of future goals and is characterized by planning and organization (i.e. "I am able to resist temptations when I know that here is work to be done", "I believe that a person's day should be planned ahead each morning”). 4) The Past-Positive scale (9 items) reflects a warm, sentimental attitude toward the past (i.e. "It gives me pleasure to think about my past”, "Happy memories of good time's spring readily to mind”). 5) The Present-Fatalistic scale (9 items) measures a helpless and hopeless attitude toward the future and life, and a sense that the future is predestined and not influenced by present individual actions (i.e. "My life path is controlled by forces I cannot influence”, The Cronbach's $\alpha$ s in the present study were: .81 for Past Positive, .87 for Past Negative, .81 for Present Hedonistic, .68 for Present Fatalistic, and .77 for Future.

\section{Variables}

1) Dependent variable: Cognitive coping and Time Perspective.

2) Independent variable: Homesickness.

\section{Operational Definition}

Cognitive Coping: Cognitive coping is conceptualized as the cognitive efforts to manage the intake of emotionally arousing stimuli. These cognitive efforts can be both voluntary and controlled as involuntary and automatic.

Time Perspective: Time Perspective defined as a cognitive tendency of individuals to be timely oriented toward the past, the present or the future. 


\section{Cognitive Coping and Time Perspective of Post Graduate Students in relation to Homesickness}

Homesickness: 'Homesickness' covers reactions to a number of circumstances which involve missing parents or family; missing friends or familiar faces; missing familiar Surroundings; feeling insecure; missing home comforts or the bedroom at home.

\section{Statistical Techniques}

The following Statistical Techniques are applied to analyze the score obtained and to verify the main hypotheses as well as their specific forms.

\section{1) Pearson's Correlation Coefficient}

The above technique is apply to verify the hypothesis $\mathrm{Ha}_{2} 2$ and to check the significant of relation of Cognitive coping strategy \& Time orientation with Home sickness in male and female students.

2) $t$ test

To study the gender differences in Cognitive coping, Time Perspective and Homesickness.

\section{RESULTS AND DISCUSSION}

The whole plan of analyzing the data started with calculation of mean and standard deviation for the scores of Homesickness, Cognitive Coping and Time Perspective of both male and female students. These results are presented in Table No. 4.01.

Table-1: Showing the Means and Standard Deviation for Homesickness, Cognitive Coping and Time Perspective of male students $(N=75)$

\begin{tabular}{|c|c|c|c|c|}
\hline SI No & Variables & Dimensions & Mean & SD \\
\hline 1 & Homesickness & & 50.19 & 9.425 \\
\hline \multirow{9}{*}{2} & \multirow{9}{*}{ Cognitive coping } & Self-blame & 53.14 & 7.827 \\
\hline & & Acceptance & 50.73 & 9.019 \\
\hline & & Rumination & 50.03 & 10.000 \\
\hline & & Positive refocusing & 47.38 & 9.585 \\
\hline & & Refocusing of planning & 49.43 & 9.154 \\
\hline & & Positive reapproval & 53.22 & 7.836 \\
\hline & & Putting into perspective & 47.43 & 9.656 \\
\hline & & Catastrophizing & 50.03 & 10.000 \\
\hline & & Other blame & 49.43 & 9.154 \\
\hline \multirow{5}{*}{3} & \multirow{5}{*}{ Time perspective } & Past negative & 50.07 & 9.459 \\
\hline & & Present hedonistic & 52.09 & 8.027 \\
\hline & & Future & 49.88 & 9.080 \\
\hline & & Past positive & 51.70 & 8.668 \\
\hline & & Present fatalistic & 52.20 & 10.490 \\
\hline
\end{tabular}

An observation of table mean score reveals that Homesickness of the male students 50.19 indicating just average. 


\section{Cognitive Coping and Time Perspective of Post Graduate Students in relation to Homesickness}

As far as Cognitive coping is concerned on some dimension $\mathrm{s}$ its above average namely selfblame (53.14) positive reappraisal (53.22) as for as the dimension of acceptance (50.73) rumination (50.03) catastrophizing (50.03) indicating that it is just average further on the dimensions namely positive reappraisal (47.38) refocus of planning (49.43) putting into perspective (47.43) and other blame (49.43) the score is below average on the dimension of Time Perspective of Time Perspective namely present hedonistic (52.09)past positive (51.70)and present fatalistic (52.20)its above average and on past positive dimension it is just average (50.07)and finally on future its below average (49.89).

Finally one can understand that all the variables Homesickness, Cognitive coping, Time Perspective are well pronounced in the male students.

Table-2: Showing the Homesickness, Cognitive Coping and Time Perspective and in terms of mean $N$ and standard deviation of Female students $(N=75)$

\begin{tabular}{|c|c|c|c|c|}
\hline SI No & Variables & Dimensions & Mean & SD \\
\hline 1 & Homesickness & & 49.81 & 10.604 \\
\hline \multirow{4}{*}{2} & Self-blame & 46.86 & 10.958 \\
\cline { 3 - 4 } & \multirow{4}{*}{ Cognitive Coping } & Acceptance & 49.27 & 10.906 \\
\cline { 3 - 4 } & & Rumination & 49.97 & 10.067 \\
\cline { 3 - 4 } & & Positive Refocusing & 52.62 & 9.778 \\
\cline { 3 - 4 } & & Refocusing of Planning & 50.57 & 10.812 \\
\cline { 3 - 4 } & & Positive Reapproval & 46.78 & 10.905 \\
\cline { 3 - 4 } & & Putting into Perspective & 52.57 & 9.734 \\
\cline { 3 - 4 } & & Catastrophizing & 49.97 & 10.067 \\
\cline { 3 - 4 } & & Other Blame & 50.57 & 10.812 \\
\hline \multirow{4}{*}{3} & \multirow{4}{*}{ Time Perspective } & Past Negative & 49.93 & 10.577 \\
\cline { 3 - 4 } & & Present Hedonistic & 47.91 & 11.317 \\
\cline { 3 - 4 } & & Future & 50.12 & 10.903 \\
\cline { 3 - 4 } & & Past Positive & 48.30 & 10.971 \\
\cline { 3 - 4 } & & Present Fatalistic & 47.80 & 9.027 \\
\hline
\end{tabular}

An observation the table reveals that Homesickness of female students are (49.81) indicating it is below average.

On Cognitive coping dimensions are concerned on positive re appraisal the mean score is (52.62) on putting into perspective (52.57) indicating that it is above average on dimension of refocus of planning it is (50.57) and on other blame (50.57) which mean that it is just average finally on the dimension of acceptance (49.27) rumination (49.97) on positive re approval (47.78) and catastrophizing (49.97) reveals that it just below average.

On Time Perspective dimensions on future it is mean score is (50.12) indicating that it is just average further table reveals on past negative (49.93) present hedonistic (47.91) past positive

(C) The International Journal of Indian Psychology, ISSN 2348-5396 (e)| ISSN: 2349-3429 (p) | 98 
(48.30) and present fatalistic (49.80) reveals it just below average. One can conclude that all the variables are significantly well pronounced in the female students.

Table-3: Showing the Homesickness, Cognitive coping and Time Perspective in terms of Mean, $N$ and standard deviation and ' $t$ ' value of female students $(N=150, M=75, F=75)$

\begin{tabular}{|c|c|c|c|c|c|}
\hline \multirow{2}{*}{ Dimensions } & \multicolumn{2}{|c|}{ Male } & \multicolumn{2}{c|}{ Female } & \multirow{2}{*}{ 't' value } \\
\cline { 2 - 5 } & Mean & SD & Mean & SD & \\
\hline Homesickness & 50.19 & 9.425 & 49.81 & 10.604 & .227 \\
\hline Self-Blame & 53.14 & 7.827 & 46.86 & 10.958 & $4.043^{* *}$ \\
\hline Acceptance & 50.73 & 9.019 & 49.27 & 10.906 & .891 \\
\hline Rumination & 50.03 & 10.000 & 49.97 & 10.067 & .039 \\
\hline Positive Refocusing & 47.38 & 9.585 & 52.62 & 9.778 & $-3.309^{* *}$ \\
\hline Refocus of Planning & 49.43 & 9.154 & 50.57 & 10.812 & -.694 \\
\hline Positive Reappraisal & 53.22 & 7.836 & 46.78 & 10.905 & $4.155^{* *}$ \\
\hline Putting in Perspective & 47.43 & 9.656 & 52.57 & 9.734 & $-3.244^{* *}$ \\
\hline Catastrophizing & 50.03 & 10.000 & 49.97 & 10.067 & .039 \\
\hline Other Blame & 49.43 & 9.154 & 50.57 & 10.812 & -.694 \\
\hline Past Negative & 50.07 & 9.459 & 49.93 & 10.577 & .089 \\
\hline Present Hedonistic & 52.09 & 8.027 & 47.91 & 11.317 & $2.608^{* *}$ \\
\hline Future & 49.88 & 9.080 & 50.12 & 10.903 & -.148 \\
\hline Past Positive & 51.70 & 8.668 & 48.30 & 10.971 & $2.105^{*}$ \\
\hline Present Fatalistic & 52.20 & 10.490 & 47.80 & 9.027 & $2.757^{* *}$ \\
\hline
\end{tabular}

${ }^{*} \mathrm{p}<0.05$ : significant

${ }^{* *} \mathrm{p}<0.01$ : highly significant

An observation of the above table reveals that the difference between male and female students is not significant ( $\mathrm{t}=.22 \mathrm{p}>.05)$ in their Homesickness, it means that the male and female students have experience the same level of Homesickness in terms of thinking about home, their friends, family and place their feeling restless and wish that they had not come to Karnatak University. On the Cognitive coping dimension namely self-blame there is significant difference between the male and female students $(\mathrm{t}=4.04 \mathrm{p}<0.01)$ it reveals that there is significant difference between the male female students on self-blame, it means that the male students have used self-blame as coping strategy in other words; they have blamed themselves, they hold themselves for what has happened, and they feel that they are the cause for feeling or experiencing Homesickness with when compared to female students.

On positive re focusing there is significant difference between the male and female students $(t=3.30 \mathrm{p}<0.01)$ the interpretation goes as, the female students have used positive refocusing as means of coping with Home sickness in other words the female students they have tried best to cope up with thoughts of pleasant things, pleasant experiences when compared to the male students. 


\section{Cognitive Coping and Time Perspective of Post Graduate Students in relation to Homesickness}

On the dimension of positive reappraisal there is significant difference between the male and female students $(t=4.15 \mathrm{p}<0.01)$ the interpretation goes as the male students have use have used the positive reappraisal as coping strategies to cope up with they have tried to learn something from the situation they have looked for positive side of the situation and they tried become strategies as a result of what has happened.

On the dimension of putting into perspective there is significant difference between male and female students $(t=3.24 \mathrm{p}<0.01)$ the interpretation as the female students have used putting into perspective as coping strategies to handle they tried console themselves by saying that other people to go through worst experiences and it could have been worse or bad when compare to the other experience of the other people.

Finally on the dimension of Cognitive coping Acceptance ( $\mathrm{t}=.89 \mathrm{p}>0.05)$, Rumination ( $\mathrm{t}=.39$ $\mathrm{p}>0.05)$, refocus of planning $(\mathrm{t}=.69 \mathrm{p}>0.05)$ there is no significant difference between male and female students on these dimensions.

On Time Perspective dimension on the present hedonistic there is significant difference between the male and female students. The Male students did things impulsively they use to listen to use favorite music, they would live life fully, try to put a lot excitement in life, liked to be with friends who were spontaneous when compared to the female students. On the dimension of past positive there is significant difference male and female students $(t=2.10 \mathrm{p}<0.01)$ the male students have been taking pleasure in thinking about their past experience, childhood sight, sounds, and smells which would bring a flood of wonderful memories, they enjoyed the stories about how things where good old times and they had many pleasant memories of the fast when compared to the female students.

On present fatalistic significant difference of male and female students $(t=2.75 \mathrm{p}<0.01)$ the interpretation goes to state that the male students believed that fate determined much of their lives, they felt that the life path controlled by forces that they could not influence and they do not make any sense of worry about their future since could not change anything . when compared to the female students.

Finally on the dimensions of past negative and future there is no significant difference between the male and female students past negative $(\mathrm{t}=.08 \mathrm{p}>0.05)$ and future $(\mathrm{t}=.14 \mathrm{p}>0.05)$.

\section{RESULTS AND DISCUSSION (CONTINUED)}

The technique of Correlation Coefficient analysis is to verify the hypotheses $\mathrm{Ha}_{2}$ the obtained correlated coefficient revealed the relationship of Homesickness, Cognitive Coping and Time Perspective in terms of direction and magnitude. 


\section{Cognitive Coping and Time Perspective of Post Graduate Students in relation to Homesickness}

Ha 1.2 $_{2}$ Self-blame, Acceptance, Rumination, Positive reappraisal, refocusing on Planning, Positive re-approval, Putting into perspective, Catastrophizing and Other blame is significantly and positively related to Homesickness of female students this Hypothesis is not proved.

Table-4: Showing correlation co efficient for Homesickness of female students with Cognitive coping strategies.

\begin{tabular}{|c|c|c|c|c|c|c|c|c|c|}
\hline \multirow{2}{*}{ Homesickness } & S B & ACC & RUM & PR & RP & PR & PIP & CAT & OB \\
\cline { 2 - 10 } & 0.47 & .00 & .08 & .00 & .00 & .012 & .01 & .08 & .00 \\
\hline
\end{tabular}

A look at the table shows the correlation co efficient between Homesickness and Cognitive coping strategies it is observed that there is no significant correlation between the dimensions namely self-blame, $(\mathrm{r}=0.4 \mathrm{p}>0.05)$ acceptance, $(\mathrm{r}=.00 \mathrm{p}>0.05)$ rumination $(\mathrm{r}=.08 \mathrm{p}>0.05)$ positive refocusing ( $\mathrm{r}=.00 \mathrm{p}>0.05)$ refocusing of planning $(\mathrm{r}=.00 \mathrm{p}>0.05)$ positive reappraisal( $\mathrm{r}=.12$ $\mathrm{p}>0.05)$ putting into perspective $(\mathrm{r}=. .001 \mathrm{p}>0.05)$ catahtrophizing $(\mathrm{r}=.08 \mathrm{p}>0.05)$ other blame $(\mathrm{r}=.00 \mathrm{p}>0.05)$.

$\mathbf{H a}_{1 \cdot 4}$ Past Positive, Past Negative, Present Hedonistic, Present Fatalistic and Future is significantly and positively related to Homesickness of female students.

Table-5: Showing the correlation coefficient for Homesickness of female students with time perspective.

\begin{tabular}{|c|c|c|c|c|c|}
\hline \multirow{2}{*}{ Homesickness } & $\begin{array}{c}\text { Past } \\
\text { Negative }\end{array}$ & $\begin{array}{c}\text { Present } \\
\text { Hedonistic }\end{array}$ & Future & $\begin{array}{c}\text { Past } \\
\text { Positive }\end{array}$ & $\begin{array}{c}\text { Present } \\
\text { Fatalistic }\end{array}$ \\
\cline { 2 - 7 } & .03 & .04 & $.24^{*}$ & $.23^{*}$ & .10 \\
\hline
\end{tabular}

$* \mathrm{P}<0.05$; Significant

A look at the table shows relationship of Time Perspective dimension of the female students with Homesickness there is significant relationship of future with Homesickness $(r=.24 ; p<0.05)$ it means that the female students with higher time orientation on for future have shown significantly higher Homesickness. It can be inferred that Homesickness of the female students significantly and positively related to Time Perspective of future. It means that female students are dreaming of family friends at home; feeling empty restlessness, realize that they cannot change fate of staying away from their family and home town. So they were started planning their future like, completing project on time, resisting the temptation when there is homework to be done given by the authorities and they wanted to catch with their work.

The relationship of Homesickness and past positive is significant $(\mathrm{r}=.23 \mathrm{p}<0.05)$ it means that the female students with high Time Perspective or past positive have shown significantly high Homesickness. It can be inferred that Homesickness of female students significantly and positively related to past positive; the interpretation goes as follows, students those high on

(c) The International Journal of Indian Psychology, ISSN 2348-5396 (e)| ISSN: 2349-3429 (p) | 101 


\section{Cognitive Coping and Time Perspective of Post Graduate Students in relation to Homesickness}

Homesickness seek pleasure in thinking about their past like childhood sights sounds smells that often bring flood of wonderful memories, they enjoying stress about how things used to be good old times and happy memories and get nostalgic about their childhood.

Further observation of the times perspective dimension namely past negative $(\mathrm{r}=.03 \mathrm{p}>0.05)$ present hedonistic $(r=.04 \mathrm{p}>0.05)$ past fatalistic $(\mathrm{r}=.10 \mathrm{p}>0.05)$ there is no significantly relationship with Homesickness.

\section{DISCUSSION}

Time orientation of female students in relation to Homesickness The findings present investigation proved that time orientation is that significantly and positively related to their Homesickness.

\section{RESULTS}

Homesickness of female students is positively and significant related to time orientation.

$\mathbf{H a}_{1 \cdot 2}$ Self-blame, Acceptance, Rumination, Positive reappraisal, refocusing on Planning, Positive re-approval, Putting into perspective, Catastrophizing and Other blame is significantly and positively related to Homesickness of female students.

Table-6: Showing the correlation coefficient for Homesickness of male students with Cognitive coping strategies

\begin{tabular}{|c|c|c|c|c|c|c|c|c|c|}
\hline \multirow{2}{*}{ Homesickness } & SB & ACC & RUM & PR & RP & PR & PIP & CAT & OB \\
\cline { 2 - 10 } & 0.89 & $0.23^{*}$ & 0.59 & 0.47 & 0.25 & 0.19 & 0.78 & 0.56 & $0.25^{*}$ \\
\hline
\end{tabular}

$* \mathrm{P}<0.05$; significant

Table shows the relationship of Homesickness Cognitive coping strategies the significant relationship of Homesickness with acceptance $(r=.23 p<0.05)$ and other blame $(r=25 p<0.05)$ the female students with higher acceptance have shown significantly Cognitive coping strategies with Homesickness, it can be inferred that Homesickness of male students is significantly positively related to Homesickness. The interpretation goes as follows the male students have accepts the situation that they have come away from home it is inevitable and they cannot change anything about their living condition and they accepting acceptance strategies as effective method of coping with Homesickness.

The relationship of other blame of the male students with Homesickness is significant $(\mathrm{r}=.25 \mathrm{p}<$ 0.05) the male students with higher Other Blame, Cognitive coping strategies have shown significantly higher Homesickness. It can be inferred that Homesickness of male students is significantly and positively related to other blame, the interpretation goes as the male students

(C) The International Journal of Indian Psychology, ISSN 2348-5396 (e)| ISSN: 2349-3429 (p) | 102 


\section{Cognitive Coping and Time Perspective of Post Graduate Students in relation to Homesickness}

are blaming others for their experience of Homesickness. They were holding others responsible what has happened and think of others mistakes that have been made in their matter and they feel others are responsible for present condition of Homesickness.

Further observation of Cognitive coping of dimensions namely Self Blame ( $\mathrm{r}=0.89>0.05)$ Rumination ( $\mathrm{r}=0.59>0.05$ ) Positive Refocusing ( $\mathrm{r}=0.47>0.05)$ Refocus of Planning $(\mathrm{r}=0.25>0.05) \quad$ Positive Reappraisal $(\mathrm{r}=0.19>0.05) \quad$ Putting into Perspective $(\mathrm{r}=0.78>0.05)$ Catastrophizing ( $\mathrm{r}=0.56>0.05)$ There is no significantly relationship with Homesickness.

Ha. .3 Past Positive, Past Negative, Present Hedonistic, Present Fatalistic and Future is significantly and positively related to Homesickness of male students.

Table-7: Showing correlation co efficient for Homesickness of male students with Time Perspective

\begin{tabular}{|c|c|c|c|c|c|}
\hline \multirow{2}{*}{ Homesickness } & $\begin{array}{c}\text { Past } \\
\text { Negative }\end{array}$ & $\begin{array}{c}\text { Present } \\
\text { Hedonistic }\end{array}$ & Future & $\begin{array}{c}\text { Past } \\
\text { Positive }\end{array}$ & $\begin{array}{c}\text { Present } \\
\text { Fatalistic }\end{array}$ \\
\cline { 2 - 6 } & 0.15 & $0.32^{* *}$ & 0.18 & 0.44 & 0.15 \\
\hline
\end{tabular}

${ }^{*} \mathrm{p}<0.01$; highly significant

On observation of the table shows the relationship of Homesickness of the male students with Time orientation dimension fast hedonistic is highly significant $(\mathrm{r}=.32 * * \mathrm{p}<0.01)$.

The male students with higher Homesickness have shown significantly higher present hedonistic time orientation to cope up with Homesickness. In other words male students have been getting together with friends, parties doing impulsively listening to their favorite music, putting excitement in life, performing with friends who are spontaneous whenever they were experiencing Homesickness.

Further on Time Perspective dimensions namely past negative $(\mathrm{r}=.15 \mathrm{p}>0.05)$, future $(\mathrm{r}=. .18$ $\mathrm{p}>0.05)$, past positive $(\mathrm{r}=.44 \mathrm{p}>0.05)$ and present fatalistic $(\mathrm{r}=.15 \mathrm{p}=>0.05)$ are not significantly related with Homesickness.

\section{DISCUSSION}

Homesickness of male students is positively and significantly related to Cognitive coping strategies and Time orientation.

Findings of the present investigations are observed to support the above assumption.

\section{RESULTS}

Homesickness of male students are positively and significantly related to Cognitive coping strategies.

(c) The International Journal of Indian Psychology, ISSN 2348-5396 (e)| ISSN: 2349-3429 (p) | 103 


\section{Cognitive Coping and Time Perspective of Post Graduate Students in relation to Homesickness}

In a study conducted by Legerstee Garnefski, Verhdst and Utens (2011) Reported that adolescents used catastrophizing, self-blame, acceptance and rumination as a Cognitive strategies. Similarly in this finding the male students have used acceptance as a Cognitive strategies.

Another study conducted by Garnefski and Kraji M.J, Schroevers, Aarnink, Vander Heijdn Van Her pen and son sent (2011) Reported that the adolescents used rumination catastrophizing and other blame as a Cognitive coping strategies similarly in our findings of the male students have used other blame as a Cognitive coping strategies. So the findings in this study are in line with the earlier conducted studies by Garnefski and Kraji M.J, and Et al (2011).

Homesickness of male students are positively and significantly related to Time orientation. In a study conducted by Fiorenzo Laghi, Pallini, Emma Baugartner and Roberto Baiocco (2015) Reported adolescents used negative past, Hedonism present and future as a time orientation similarly in this findings the male students have used present hedonistic as a time orientation.

\section{CONCLUSION}

1) There is significant difference between the male and female students on Homesickness.

2) The male students have expressed significant self-blame as coping strategies when compared with the female students.

3) The male students have expressed positive refocusing as Cognitive coping strategies when compared with male students.

4) The female students have adapted refocus of planning as Cognitive coping strategies when compared with male students.

5) The male students have adapted positive appraisal as Cognitive coping strategies when compared with female students.

6) The female students have used putting into perspective approach to cope up with compared with male students.

7) The male students time orientation is present hedonistic when compared to female students.

8) The male student's time orientation is on present fatalistic when compared to female students.

9) The female students with high time orientation of future have shown significantly higher Homesickness.

10) The female students with high on Time Perspective of past positive have shown significantly high on Homesickness.

11) The male students with high Homesickness have shown significantly high acceptance Cognitive coping strategies.

12) The male students with high Homesickness have shown significantly higher on other blame Cognitive coping strategies.

(C) The International Journal of Indian Psychology, ISSN 2348-5396 (e)| ISSN: 2349-3429 (p) | 104 


\section{Cognitive Coping and Time Perspective of Post Graduate Students in relation to Homesickness}

13) The male students with high Homesickness have shown significantly higher present hedonistic time perspective.

\section{Social Implication}

The finding of the study reflects the prevailing state of male and female students as far as Homesickness , Cognitive coping strategies and Time Perspective is concerned their calls for a special attention research to plan for intervention program to enhance the cognitive coping strategies to cope up Homesickness similarly the time orientation helps in knowing which of the subject would probably would be susceptible to Homesickness their helps the counselor to help the client to cope up Homesickness.

\section{Acknowledgments}

The author appreciates all those who participated in the study and helped to facilitate the research process.

\section{Conflict of Interests}

The author declared no conflict of interests.

\section{REFERENCES}

Abdi, S., Taban, S., \& Ghaemian, A. (2012). Cognitive emotion regulation questionnaire: Validity and reliability of Persian translation of CERQ-36 item. Procedia - Social and Behavioral Sciences, 32, 2-7. doi:10.1016/j.sbspro.2012.01.001

Boyd, John N.; Zimbardo, Philip G. Strathman, Alan (Ed); Joireman, Jeff (Ed). (2005). Understanding behavior in the context of time: Theory, research, and application (pp. 85-107). Mahwah, NJ, US: Lawrence Erlbaum Associates Publishers, xix, 356 pp.

Brewin, C. R., Furnham, A., \& Howes, M. (1989). Demographic and psychological determinants of homesickness and confiding among students. British Journal of Psychology, 80(4), 467-477. doi:10.1111/j.2044-8295.1989.tb02336.x

Cretu, R. Z., \& Negovan-Zbăganu, V. (2013). An Exploratory Approach of the Structure of Zimbardo's Time Perspective Concept. Procedia - Social and Behavioral Sciences, 78, 753-757. doi:10.1016/j.sbspro.2013.04.389

Garnefski, N., \& Kraaij, V. (2006). Cognitive emotion regulation questionnaire - development of a short 18-item version (CERQ-short). Personality and Individual Differences, 41(6), 1045-1053. doi:10.1016/j.paid.2006.04.010

Garnefski, N., Legerstee, J., Kraaij, V., Kommer, T. V., \& Teerds, J. (2002). Cognitive coping strategies and symptoms of depression and anxiety: A comparison between adolescents and adults. Journal of Adolescence, 25(6), 603-611. doi:10.1006/jado.2002.0507

Kraaij, V., Garnefski, N., Schroevers, M. J., Weijmer, J., \& Helmerhorst, F. (2010). Cognitive Coping, Goal Adjustment, and Depressive and Anxiety Symptoms in People Undergoing 


\section{Cognitive Coping and Time Perspective of Post Graduate Students in relation to Homesickness}

Infertility Treatment: A Prospective Study. Journal of Health Psychology, 15(6), 876886. doi:10.1177/1359105309357251

Roche, A., \& Frankel, A. (1986). Time perspective and health. Health Education Research Health Educ Res, 1(2), 139-142. doi:10.1093/her/1.2.139

Shal, R. S., Sharbaf, H. A., Abdekhodaee, M. S., Masoleh, S. M., \& Salehi, I. (2011). Survey the Relationship Between Attachment Style and General Self Efficacy with Homesickness Among College Students. Procedia - Social and Behavioral Sciences, 30, 538-541. doi:10.1016/j.sbspro.2011.10.105

Thurber, C. A., \& Walton, E. A. (2012). Homesickness and Adjustment in University Students. Journal of American College Health, 60(5), 415-419. doi:10.1080/07448481.2012.673520

How to cite this article: A Patil, R Kulkarni S Kamle (2016), Cognitive Coping and Time Perspective of Post Graduate Students in relation to Homesickness, International Journal of Indian Psychology, Volume 3, Issue 4, No. 65, ISSN 2348-5396 (e), ISSN: 2349-3429 (p), DIP: 18.01.144/20160304, ISBN: 978-1-365-34680-4 